ment will be to encourage the new medical generation to take a positive role in the battle for the environment and to encourage the profession as a whole to adopt this role, which lamentably it has failed to do so far. As the doctors of tomorrow, today's medical students are not prepared to suffer the devastating consequences to health of today's environment.

In conclusion, the organizers of this symposium have asked me to express their whole-hearted support for the aims of those whose recent letter ( 8 January, p. 108) urged extensive action on the problem of population control. It is their hope that other members of the medical profession will be encouraged to do likewise.-I am, etc.,

South Bridge,

Peter BerRey Edinburgh

\section{Laxative Jaundice}

SiR,-You say (5 February, p. 325) that cases of chronic active hepatitis associated with the use of oxyphenisatin are the first in which a drug has been implicated. Histological changes resembling chronic active hepatitis have, however, been recorded in two patients treated with methyl dopa, ${ }^{12}$ though the characteristic clinical and biochemical features were absent. We are at present preparing a report of four patients in whom the full syndrome of chronic active hepatitis appeared to follow the use of methyl dopa in two and the contraceptive pill in two. It is important that such patients be questioned carefully about drug taking including preparations used for self-medication.-I am, etc.,

Dudley Road Hospital,

A. Paton Birmingham

1 Morin, Y., Turmel, L., and Fortier, J., American 2 Williams, E. R., and Khan, M. A., Yournal of Therapeutics and Clinical Research, 1967, 1, 5.

\section{Herpes Encephalitis in Pregnancy}

SIR,-We have recently had the opportunity to observe herpes simplex encephalitis in a young woman who delivered a live child during the course of her fatal illness. We believe the virological and histological findings strongly suggest direct neural transmission without viraemic spread.

A 19-year-old woman presented near term with a pharyngitis and pyrexia and during the next 10 days progressively developed dysphasia, right hemiparesis, hemihypaesthesia, hemianopia, and deterioration in conscious level. Technetium brain scan and left carotid arteriography showed a large left temporal space occupying lesion. Biopsy of this showed evidence of encephalitis and positive fluorescent antibody study to herpes simplex virus, which was subsequently cultured from ventricular cerebrospinal fluid and the biopsy. Treatment with intravenous idoxuridine, $2.5 \mathrm{~g}$ in $500 \mathrm{ml} 5 \%$ dextrose 8 hourly was unavailing and she died two days later.

At necropsy the brain was swollen and there was necrosis of both olfactory bulbs and tracts and the left temporoparietal and hippocampal regions. Cowdry type $A$ intranuclear inclusions were found in the right temporal lobe.
Five days before she died she was delivered of a live child, who remained healthy. No antibody to herpes simplex was demonstrable in his blood when he was 23 days old.

Buddingh et al.1 found that in primary herpetic stomatitis neutralizing antibodies were first demonstrated in the serum from the fourth to the seventh day of the disease and that maximal levels were found during the second and third week. They also demonstrated transplacental transfer of antibody. Herpetic infection in neonates is frequently fatal whether or not circulating antibody is present. The absence of an antibody response in the mother together with the absence of antibody and clinical infection in the infant make it unlikely that the virus was spread by the bloodstream. As well as dissemination by blood, Johnson and $\mathrm{Mims}^{2}$ demonstrated that virus could reach the central nervous system by spread across the olfactory mucosa and infection of endoneural or perineural cells. The necropsy findings of olfactory bulb, tract, and hippocampal necrosis together with virus isolation from temporal lobe lend support to the hypothesis that in this case the virus spread by the direct neural and not the haematogenous route.

Our previous experience with idoxuridine in herpes simplex encephalitis (admittedly small, four cases) has left us unconvinced of its therapeutic value. However, the present case was in such a critical condition at the time of administration that her death could hardly be attributed to lack of action of the drug. - We are, etc.

J. M. ANDERSON

M. W. N. NichOLLS

Midland Centre for Neurosurgery and Neurology, Smethwick, Worcs

1 Buddingh, G. J., Schrum, D. I., Lanier, J. C.,
anc Fuidry, D. J., Pediatrics, 1953, M11. 595.
2 Johnson, R. T., and Mims, C 2 Johnson, R. T., a d. Mims, C. A., New England

Hypothyroidism after Partial Thyroidectomy

SIR,-Mr. W. Michie and his colleagues (1 January, p. 13) report a $49 \%$ incidence of hypothyroidism in patients who had undergone a thyroidectomy up to seven years previously. From this data clearly a careful follow-up of these patients is essential. Their discovery that a serum P.B.I. at one and four months after operation gave an indication of the future status of the individual patient makes this investigation obligatory where a subtotal excision has previously been performed.

In a busy outpatient clinic the important clinical assessment of these patients may be passed to the junior staff after some months. For this reason, regrettably, the patient may well see a different doctor on almost every visit. Subtle changes in facial appearance may thus be missed unless photographs of the patient taken at the time of the origina surgery are included in the notes. Mr. Michie states that in their cases neither clinical nor E.C.G. evidence of hypothyroidism was seen until three years postoperatively. However, comparison of the patients' features with a photograph taken at the time of surgery may allow much earlier clinical diagnosis of thyroidism-a useful adjunct to the biochemical data.-I am, etc.,

Frenchay Hospital,
Bristol

RoY E. MAY

\section{Hyperpyrexia and Overdose}

SIR,-We would like to record an unusual case of malignant hyperpyrexia associated with overdosage of fenfluramine.

A 34-year-old housewife with a long history of anxiety depression including many previous suicide attempts was admitted to our hospital with a history of having apparently taken 50 fenfluramine tablets. On admission she was drowsy but able to hold a conversation. However, over the next 20 minutes she became unconscious, began to hyperventilate, developed tachycardia, and began to sweat profusely. At this time she also went rigid, flexing her arms and legs and moving her forearms with irregular writhing movements. She also developed coarse rolling movements of the eyes in all directions.

She was given diazepam $10 \mathrm{mg}$ intravenously, followed by $10 \mathrm{ml}$ of calcium gluconate intravenously and $100 \mathrm{mg}$ chlorpromazine intramuscularly, to no effect. At this point she was given succinylcholine, intubated, and artifically ventilated, as her breathing had become stertorous. Following this her rigidity disappeared, and within about 15 minutes her skin was noted to be hot and dry. Her rectal temperature on two successive readings was found to be $109^{\circ} \mathrm{F}\left(42 \cdot 8^{\circ} \mathrm{C}\right)$. An attempt was made to reduce her temperature by conventional means, and it was decided to use procaine intravenously to treat her hyperpyrexia, as described by Harrison. ${ }^{1}$ The patient was given an infusion of $5 \%$ dextrose saline with $60 \mathrm{mg}$ of procaine as a loading dose. This, in fact, was only one-sixth of the recommended dose because, as the infusion started, her blood pressure dropped from 100 systolic to 70 systolic. She was then given a maintenance dose of $0.2 \mathrm{mg} / \mathrm{kg} / \mathrm{min}$ of intravenous procaine over the next two hours. Isoprenaline was not given as recommended, because of her tachycardia of 180 . Within about half-an-hour her temperature dropped to $90^{\circ} \mathrm{F}\left(33^{\circ} \mathrm{C}\right)$. Her blood pressure remained at about $70 \mathrm{~mm} / \mathrm{Hg}$ systolic despite plentiful fluid replacement. During the subsequent hours her blood pressure became unrecordable and she died about $13 \frac{1}{2}$ hours after admission.

In four recorded fatalities ${ }^{2}$ following fenfluramine overdose, all associated with overdosage greater than 90 tablets, there was a rise in blood pressure, hyperventilation, sweating, clonic convulsions followed by rigidity of the limbs, and usually a fatal cardiac arrhythmia. In all of these cases a high temperature was recorded. In one case of a 13-year-old child taking an overdose of fenfluramine the temperature went up to $107^{\circ} \mathrm{F}$ $\left(41 \cdot 7^{\circ} \mathrm{C}\right)^{2}$

We felt that the hyperpyrexia was due to fenfluramine overdosage rather than being succinylcholine-induced, because of the short space of time which elapsed between giving the succinylcholine and recording a temperature of $109^{\circ} \mathrm{F}\left(42 \cdot 8^{\circ} \mathrm{C}\right)$. The maximum rate of rise in temperature in malignant hyperpyrexia is said to be $1^{\circ} \mathrm{F}$ per $5-10$ minutes. ${ }^{3}$ One case in which procainamide has been used successfully in the treatment of malignant hyperpyrexia has been recorded.4 Procaine has been shown to give some benefit in treating Landrace pigs with hyperpyrexia. ${ }^{1}$ Chlorpromazine $^{5}$ has also been used in the successful treatment of malignant hyperpyrexia, and a review of the methods of treatment for this condition is in preparation. ${ }^{6}$ To exclude any hereditary myopathy which might have caused this alarming pyrexial response in this patient we are in the process of estimating creatine phosphokinase and aldolase in the sera of other members of this patient's family. In our case, procaine and conservative measures reduced the temperature very rapidly but the patient died, possibly because the blood levels were in fact extremely high and 